Review article

\title{
Lipidome signatures in early bovine embryo development
}

\author{
Mateus J. Sudano a,*, Tatiana D.S. Rascado ${ }^{\mathrm{b}}$, Alessandra Tata ${ }^{\mathrm{c}}$, \\ Katia R.A. Belaz ${ }^{c}$, Vanessa G. Santos ${ }^{c}$, Roniele S. Valente ${ }^{a}$, \\ Fernando S. Mesquita a, Christina R. Ferreira ${ }^{c}$, João P. Araújo ${ }^{d}$, \\ Marcos N. Eberlin ${ }^{c}$, Fernanda D.C. Landim-Alvarenga ${ }^{b}$ \\ a School of Veterinary Medicine, Federal University of Pampa, Uruguaiana, RS, Brazil \\ ${ }^{\mathrm{b}}$ Department of Animal Reproduction and Veterinary Radiology, School of Veterinary Medicine and Animal Science, São Paulo State \\ University, Botucatu, SP, Brazil \\ ${ }^{\mathrm{c}}$ ThoMSon Mass Spectrometry Laboratory, Institute of Chemistry, University of Campinas, Campinas, SP, Brazil \\ ${ }^{\mathrm{d}}$ Department of Microbiology and Immunology, Biosciences Institute, São Paulo State University, Botucatu, SP, Brazil
}

\section{Keywords:}

Embryogenesis

Membrane phospholipids

Cytoplasmic lipid droplets

Long chain acyl-CoA synthetizes

Elongation of very long fatty acids

\begin{abstract}
A B S T R A C T
Mammalian preimplantation embryonic development is a complex, conserved, and wellorchestrated process involving dynamic molecular and structural changes. Understanding membrane lipid profile fluctuation during this crucial period is fundamental to address mechanisms governing embryogenesis. Therefore, the aim of the present work was to perform a comprehensive assessment of stage-specific lipid profiles during early bovine embryonic development and associate with the mRNA abundance of lipid metabolismrelated genes (ACSL3, ELOVL5, and ELOVL6) and with the amount of cytoplasmic lipid droplets. Immature oocytes were recovered from slaughterhouse-derived ovaries, two-cell embryos, and eight- to 16-cell embryos, morula, and blastocysts that were in vitro produced under different environmental conditions. Lipid droplets content and mRNA transcript levels for ACSL3, ELOVL5, and ELOVL6, monitored by lipid staining and quantitative polymerase chain reaction, respectively, increased at morula followed by a decrease at blastocyst stage. Relative mRNA abundance changes of ACSL3 were closely related to cytoplasmic lipid droplet accumulation. Characteristic dynamic changes of phospholipid profiles were observed during early embryo development and related to unsaturation level, acyl chain length, and class composition. ELOVL5 and ELOVL6 mRNA levels were suggestive of overexpression of membrane phospholipids containing elongated fatty acids with 16, 18, and 20 carbons. In addition, putative biomarkers of key events of embryogenesis, embryo lipid accumulation, and elongation were identified. This study provides a comprehensive description of stage-specific lipidome signatures and proposes a mechanism to explain its potential relationship with the fluctuation of both cytoplasmic lipid droplets content and mRNA levels of lipid metabolism-related genes during early bovine embryo development.
\end{abstract}

(c) 2016 Elsevier Inc. All rights reserved.

\section{Introduction}

Mammalian preimplantation embryonic development is a complex, conserved, and well-orchestrated process

\footnotetext{
* Corresponding author. Tel.: +55 55 3911-0200×2293; fax: +55 55 3911-0200.

E-mail address: mjsudano@gmail.com (M.J. Sudano).
}

involving dynamic molecular and structural changes during the embryogenesis period [1]. Embryos must undergo important events, such as fertilization, cleavage, epigenetic reprogramming, compaction, differentiation, and blastulation, for the proper development and pregnancy establishment [2,3]. A series of holistic experiments evaluating transcriptome and proteome during early bovine embryonic development have been performed 
addressing the fluctuation of gene transcripts and proteins associated with important biologic process that occurs during this period [1,3-5].

Previous studies were conducted to assess the lipidome of mouse [6] and bovine [7,8] oocytes and preimplantation embryos. However, a comprehensive lipid analysis of stagespecific lipidome signatures is still lacking.

Lipids are essential biomolecules of cells as a component of the plasma membrane and the membranes of various organelles. They are also directly involved in signal transduction as lipid mediators including phosphatidylinositols, sphingolipids, and eicosanoids [9]. Lipids also play important roles in a series of key biologic process including cell proliferation, migration, differentiation, chemotaxis, pinocytosis, survival, and metabolic changes $[10,11]$. Lipids potentially serve as signaling molecules that help co-ordinate fundamental events during embryo development, implantation, and post-implantation growth [9,12,13].

Triglycerides (TAG), the major lipid class found in the cytoplasm of mammalian cells, are stored as lipid droplets $[14,15]$. For the early embryonic development, lipid droplets seem to work as a source of energy for oocytes and embryos [16,17]. In eukaryotic cell membranes, however, phospholipids (PLs) are the most abundant lipids [18]. Phospholipids, most particularly, phosphatidylcholines (PC), phosphatidylethanolamine (PE), and sphingomyelins (SM) are structural units of functional membranes, and their composition determines most of the physicochemical cell membrane properties, including fluidity, permeability, and thermal phase behavior [19].

It has already been described the effect of different environmental conditions in the number of cytoplasmic lipid droplets [20] and lipid profile [21] of in vitro-produced bovine embryos. Additionally, changes in lipid membrane composition were monitored by matrix-assisted laser desorption ionization mass spectrometry (MALDI-MS) comparing Bos taurus indicus and Bos taurus taurus and in vivo- and in vitro-derived blastocysts [22]. Furthermore, lipid-processing molecules (long-chain acyl-CoA synthetases [ACSLs] and elongation of very long fatty acids [ELOVLs]) that may be potentially involved with membrane lipid metabolic pathways in bovine embryos were identified [23].

ACSLs are a family of enzymes (ACSL1, 3, 4, 5, and 6) that activate long-chain fatty acids to generate long-chain acylCoA, essential substrate for the synthesis of various lipid species, including TAG, cholesterol ester, and PL [24,25]. These enzymes have already been related to the modulation of cell fatty acid uptake [26]. ELOVL family members (ELOVL1 to 7) are responsible for elongation of fatty acids to generate very long chain of saturated, monounsaturated, and polyunsaturated fatty acids [27,28]. Both ACSL and ELOVL enzyme family members are expected to be involved in the lipid metabolism of preimplantation bovine embryos. In a preliminary study, in vitro-produced embryos that presented greater lipid content than in vivo counterparts also reported increased mRNA levels for ACSL3, whereas Bos taurus embryos that had more lipid droplets and increased cryosurvival compared with Bos indicus embryos also presented with increased mRNA levels for ELOVL5 [23]. Additionally, ELOVL6 enzyme is known to elongate palmitic and palmitoleic fatty acids [28], abundant fatty acids during early embryo development [29].

The objective of present work was, therefore, to comprehensively assess the stage-specific lipid profiles during early development of in vitro-produced bovine embryos and associate with the mRNA levels of lipid metabolism-related genes (ACSL3, ELOVL5, and ELOVL6) and with the amount of cytoplasmic lipid droplets.

\section{Materials and methods}

\subsection{Reagents used}

All materials were acquired from Sigma (Sigma-Aldrich Corp., St. Louis, MO, USA), except when specified.

\subsection{Experimental design}

To obtain the stage-specific lipid profiles, cytoplasmic lipid droplets content and mRNA transcript levels of lipid metabolism-related genes during early bovine embryo development, five in vitro developmental stages were assessed: immature oocytes ( -24 hours post-insemination [hpi], considered as the start point of lipids measurement), two-cell embryos (32-40 hpi), eight- to 16-cell embryos (72 hpi), morulas (120 hpi), and blastocysts (168 hpi). Two different in vitro culture environmental conditions were used for embryo production: modified synthetic oviduct fluid (SOFaaci) and synthetic oviduct fluid-bovine embryo 1 (SOF-BE1) media. All samples were immediately frozen or stored after oocyte selection for further evaluation as previously described $[22,23,30]$.

\subsection{Embryo production}

In vitro production (IVP) of bovine embryos was performed as previously described [22,31], unless otherwise noted. Only oocytes with three or more compact layers of cumulus cells and homogeneous cytoplasm were used. Selected oocytes were in vitro matured (IVM) by incubation at $38.5{ }^{\circ} \mathrm{C}$ in $5 \% \mathrm{CO}_{2}$ in air with saturated humidity for 24 hours. Drops containing $90 \mu \mathrm{L}$ of TCM 199 with Earle salts and L-glutamine (Gibco, Invitrogen Co., Grand Island, NY, USA), supplemented with $5 \mathrm{mg} / \mathrm{mL} \mathrm{BSA}$ (fatty acid free), $0.2 \mathrm{mM}$ sodium pyruvate, $5 \mathrm{mg} / \mathrm{mL}$ LH (Lutropin-V; Bioniche Co., Belleville, ON, Canada), $1 \mathrm{mg} / \mathrm{mL} \mathrm{FSH}$ (Folltropin; Bioniche Co.), $100 \mu \mathrm{g} / \mathrm{mL}$ of streptomycin sulfate, and $100 \mathrm{IU} / \mathrm{mL}$ of penicillin (Gibco, Invitrogen Co.), containing 20 to 30 oocytes each, were placed in petri dishes and covered with mineral oil. At the end of the in vitro maturation period, groups of 20 to 30 oocytes were fertilized with Percoll-purified sperm [32], at the concentration of $2 \times 10^{6} \mathrm{sperm} / \mathrm{mL}$ in $90 \mu \mathrm{L}$-containing drops of fertilization media covered with mineral oil. Fertilization occurred in modified Tyrodes for in vitro fertilization medium [32] supplemented with $6 \mathrm{mg} / \mathrm{mL} \mathrm{BSA}$ (fatty acid free; Sigma A8806), $0.2 \mathrm{mM}$ pyruvate, $30 \mu \mathrm{g} / \mathrm{mL}$ heparin, $18 \mu \mathrm{M}$ penicillamine, $10 \mu \mathrm{M}$ hypotaurine, $1.8 \mu \mathrm{M}$ epinephrine, $100 \mu \mathrm{g} / \mathrm{mL}$ streptomycin sulfate, and $100 \mathrm{IU} / \mathrm{mL}$ penicillin (Gibco, Invitrogen Co.). Oocytes and sperm were incubated under the same conditions as IVM for approximately 
18 hours. After incubation, presumptive zygotes were denuded by repeated pipetting and randomly transferred to culture plates under drops (20-30 structures per drop) containing $90 \mu \mathrm{L}$ of SOFaaci or SOF-BE1, covered with mineral oil. Note that the experimental model included, by design, two distinct, but commonly used, culture media conditions aiming to control for the confounding effect of the culture media composition. Stage-specific lipidome signatures identified during early embryo development should represent temporal, developmentally modulated changes. In vitro culture was performed at $38.5{ }^{\circ} \mathrm{C}$ in an atmosphere of $5 \% \mathrm{CO}_{2}$ and $5 \% \mathrm{O}_{2}$ with the balance $\mathrm{N}_{2}$. The SOFaaci [33] medium was composed by $107.63 \mathrm{mM} \mathrm{NaCl}$, $7.16 \mathrm{mM} \mathrm{KCl}, 1.19 \mathrm{mM} \mathrm{KH}_{2} \mathrm{PO}_{4}, 1.51 \mathrm{mM} \mathrm{MgSO}_{4}, 1.78 \mathrm{mM}$ $\mathrm{CaCL}_{2} \cdot 2 \mathrm{H}_{2} \mathrm{O}, 5.35 \mathrm{mM}$ sodium lactate, $25.0 \mathrm{mM} \mathrm{NaHCO}$, $0.2 \mathrm{mM}$ sodium pyruvate, $0.20 \mathrm{mM}$ L-glutamine, $45.0 \mu \mathrm{L} / \mathrm{mL}$ basal medium eagle essential amino acids $(50 \times), 5.0 \mu \mathrm{L} / \mathrm{mL}$ minimum essential medium nonessential $(100 \times), 0.34 \mathrm{mM}$ trisodium citrate, $2.77 \mathrm{mM}$ myo-inositol, $10 \mu \mathrm{g} / \mathrm{mL}$ phenol red, and supplemented with $2.5 \%$ fetal calf serum (FCS), $5 \mathrm{mg} / \mathrm{mL}$ BSA (fatty acid free; Sigma A8806), $100 \mu \mathrm{g} / \mathrm{mL}$ streptomycin sulfate, and $100 \mathrm{IU} / \mathrm{mL}$ of penicillin (Gibco, Invitrogen Co.). The SOF-BE1 composition was $107.7 \mathrm{mM}$ $\mathrm{NaCl}, 7.16 \mathrm{mM} \mathrm{KCl}, 1.19 \mathrm{mM} \mathrm{KH}_{2} \mathrm{PO}_{4}, 0.49 \mathrm{mM} \mathrm{MgCL} 2 \cdot 6 \mathrm{H}_{2} \mathrm{O}$, $1.17 \mathrm{mM} \mathrm{CaCL} \cdot 2 \mathrm{H}_{2} \mathrm{O}, 5.30 \mathrm{mM}$ sodium lactate, $25.07 \mathrm{mM}$ $\mathrm{NaHCO}_{3}, 0.4 \mathrm{mM}$ sodium pyruvate, $1.00 \mathrm{mM}$ alanyl glutamine, $20 \mu \mathrm{L} / \mathrm{mL}$ basal medium eagle essential amino acids (50×), $10 \mu \mathrm{L} / \mathrm{mL}$ minimum essential medium nonessential $(100 \times), 0.50 \mathrm{mM}$ trisodium citrate, $2.77 \mathrm{mM}$ myo-inositol, supplemented with $4.0 \mathrm{mg} / \mathrm{mL}$ BSA (fatty acid free; Sigma A8806), and $25.0 \mu \mathrm{L} / \mathrm{mL}$ gentamicin sulfate, as previously described [34]. Embryos remained in this condition until Day 7 post-insemination. Immature oocytes $(-24 \mathrm{hpi}$; denuded by repeated pipetting) and embryos at the twocell stage (32-40 hpi), eight- to 16-cell embryos (72 hpi), morula (120 hpi), and blastocyst (168 hpi) were collected for lipid profiling by MALDI-MS and staining with Nile Red for cytoplasmic lipid droplets visualization and for quantitative polymerase chain reaction (qPCR) evaluation of lipid metabolism-related genes. A total of 2000 oocytes were used in seven IVP replicates to achieve all the required embryos for the experiments. Cleavage $(80.0 \%$ and $80.3 \%)$ and blastocyst (38.3\% and $25.0 \%$ ) rates were similar for SOFaaci and SOF-BE1 media, respectively. Embryos of each development stage were recovered randomly from each IVP replicate from individual drops used just to collect a specific stage avoiding the use of the same drop to produce early and than later stages.

\subsection{Cytoplasmic lipid droplets staining}

A sample of denuded immature oocytes $(n=8)$ and of each early embryo development stage (two-cell embryos, eight- to 16-cell embryos, morula, and blastocyst stages; $\mathrm{n}=5-9$ per stage, from each of the two culture media) were randomly selected during experimental replications and stained with Nile Red (Molecular Probes, Eugene, OR, USA), a fluorescent dye for intracellular lipid droplets, as previously described $[35,36]$. Denuded oocytes and embryos were washed in a solution of $0.1 \%(\mathrm{wt} / \mathrm{vol})$ polyvinylpyrrolidone in phosphate-buffered saline solution
(PVP-PBS) and fixed in 4\% (vol/vol) formaldehyde in PVPPBS solution during 1 hour. A stock solution was prepared by dissolving Nile Red in DMSO at a concentration of $1 \mathrm{mg} /$ $\mathrm{mL}$ and stored at $-20{ }^{\circ} \mathrm{C}$. Oocytes and embryos were stained with a work solution of $15 \mu \mathrm{g} / \mathrm{mL}$ of Nile Red in PVP-PBS solution during 1 hour in the dark at room temperature. Final concentration was obtained by diluting the stock with the PVP-PBS. Stained structures were washed again in PVP-PBS and mounted in $10 \mu \mathrm{L}$ glycerol on cover slips and examined under a fluorescence microscope to take a digital photograph at the equatorial plane of the oocyte and embryo at $\times 400$ magnification in the microscope focus that had the greater number of lipid droplets. Fluorescence intensity (FI) was quantified using Image J $1.47 \mathrm{t}$ software (version 1.60_65, Wayne Rasband; National Institutes of Health, Washington DC, USA). Oocyte and embryo color pictures were converted to a gray-scale image and oocyte/embryos were delimited (using the freehand selection tool on ImageJ) to obtain area $\left(\mu \mathrm{m}^{2}\right)$ and gray intensity mean (arbitrary unit). Background was removed (considering where no embryo was present to be zero to compensate for variation of the UV lamp intensity) by subtracting the value where no embryo was present from the measurement of the oocyte and embryo, and the gray intensity mean per area was calculated (arbitrary units/ $\mu \mathrm{m}^{2}$ ) and presented as FI (mean/area).

\subsection{Lipid profiling by MALDI-MS}

\subsubsection{Sample preparation}

Denuded immature oocytes $(\mathrm{n}=6$ pools containing five immature oocytes each) and early development stage embryos (two-cell embryos, eight- to 16-cell embryos, morula, and blastocyst; $\mathrm{n}=11-17$ single embryos/stage) were washed five times in drops of PBS solution and stored in microtubes containing 2 to $4 \mu \mathrm{L}$ of PBS at $-80{ }^{\circ} \mathrm{C}$ until analysis. Samples were thawed by pipetting $100 \mu \mathrm{L}$ of a solution of 1:1 (vol/vol) methanol/ultrapure water (ACS/HPLC grade; Burdick and Jackson, Muskegon, MI, USA, and Millipore, Bedford, MA, USA) into the microtube and washed five times in the same solution. Each embryo or pool of five oocytes was placed on a unique spot on the MALDI target plate under the stereomicroscope. Samples were allowed to dry at room temperature, and their location was recorded on a map. Just before analysis, $1 \mu \mathrm{L}$ of $1.0 \mathrm{M}$ of $2,5-$ dihydroxybenzoic acid diluted in pure methanol was deposited on each target spot to cover the embryos, and the spots were allowed to dry at room temperature.

\subsubsection{MALDI-MS data acquisition}

MALDI-MS and matrix-assisted laser desorption/ ionization-tandem mass spectrometry (MALDI-MS/MS) data were acquired in reflectron mode using an Autoflex III MALDI time-of-flight mass spectrometer (Brucker Daltonics, Bremen, Germany) equipped with smart beam laser technology. The mass spectra were acquired in the $\mathrm{m} / \mathrm{z}$ 700 to 1200 range, in positive ion mode, by averaging 1500 consecutive laser shots with a frequency of 200 until signals in the region of interest were observed and then disappeared due to the consumption of the sample. MALDI-MS/MS was manually performed by increasing the 
collision energy until extensive dissociation of the precursor ion was observed. Argon was used as the collision gas. FlexAnalysis 3.3 software (Brucker Daltonics) was used to check the mass spectra. The most intense ions, which were clearly distinct from noise after the exclusion of isotopic peaks, were considered from each spectrum and used as the starting point to search for $m / z$ values corresponding to lipids.

\subsubsection{Lipid assignment}

MALDI-MS/MS (laser-induced fragmentation technique [LIFT]) analysis was performed to confirm the structure of lipid species that were significant for experimental group differentiation. To increase the intensity of the signal and simplify the isolation of the parent ions, a pool of 10 oocytes/embryos per group was placed on each spot. The LIFT data, data previously obtained in the literature $[21,22,30,37,38]$, and two lipid databases (http:// lipidsearch.jp or www.lipidmaps.org) were used to assign PL (PC, PE, and SM) and triacylglycerol species.

\subsection{Determination of the relative abundance of $m R N A$ transcripts for ACSL3, ELOVL5, and ELOVL6}

Relative mRNA abundance fluctuation of target genes involved in lipid metabolism throughout embryo development was evaluated in a total of four and eight biologic replicates (pools) for immature oocytes and early embryos, respectively. Pools of 20 (for immature oocytes), 15 (for two-cell embryos, eight- to 16-cell embryos, and morula), and seven (for blastocyst) structures were submitted to total RNA extraction using the RNeasy Micro kit (Qiagen, Mississauga, ON, Canada) followed by DNase treatment (Qiagen) and reverse transcription (Oligo-dT primer and SuperScript III; Applied Biosystems, Foster City, CA, USA). The cDNA equivalent of two embryos was used for the evaluation of transcript abundance for ACSL3, ELOVL5, and ELOVL6 and housekeeping genes GAPDH, SDHA, and YWHAZ in a 7300 Real Time PCR System (qPCR; Applied Biosystem) using GoTaq qPCR Master Mix (Promega, Madison, WI, USA). PCR conditions were as follows: 2 minutes at $95{ }^{\circ} \mathrm{C}$ followed by 40 cycles each of 15 seconds at $95{ }^{\circ} \mathrm{C}$, and 1 minute at $60^{\circ} \mathrm{C}$. Data were analyzed using the standard curve method [39]. The reference gene was the geometric mean of the $\mathrm{Ct}$ values of GAPDH, SDHA, and YWHAZ [40]. The ACSL3 (5'CCACAGACTTTAGCAGATCAGTCTT3' and 5'CG ATCCATGATTTCCGGGAC3'), ELOVL5 (5'GGCCACATCAGCA GCTTTTC3' and 5'ACGATGTGGTTCAGAGGCTG3'), and ELOVL6 (5'TCAGTTGCCTTGGGCTTTCA3' and 5'CCCAGCTCAAGAACTT CGGT3 $^{\prime}$ ) primer pairs were used. Others primer pairs (GAPDH, SDHA, and YWHAZ) were published previously [40].

\subsection{Statistical analysis}

For cytoplasmic lipid droplets content and transcript abundance evaluation, data were analyzed with ANOVA using the generalized linear mixed model (GLIMMIX) procedure with the SAS statistical software package (SAS Institute Inc., Cary, NC, USA). Sources of variation in the model included development stage (immature oocytes, two-cell embryos, eight- to 16 -cell embryos, morula, and blastocyst), culture media (SOFaaci and SOF-BE1), replicate, and first other interaction. All factors, except replicate, were considered to be fixed effects. If the ANOVA was significant, means were separated using Tukey's test. Logarithmic transformation was applied to $\mathrm{qPCR}$ data to improve normality. The data are reported as untransformed leastsquares means \pm SEM.

For mass spectrometry lipid profiles analysis, multivariate and univariate statistical models were used. Missing values were replaced by the half of the minimum positive value in the data obtained from the preprocessing procedure. The intensity values of each peak across multiple spectra were autoscaled (mean-centered and divided by the standard deviation of each variable) to give the same importance to every $m / z$ value. Partial least square discriminant analysis (PLS-DA) was performed using the MetaboAnalyst 2.0 [41] to show the relationship between variance in the data and differences among embryo development stage (immature oocytes, two-cell embryos, eight- to 16-cell embryos, morula, and blastocyst) samples. The differentially expressed lipid species between early embryo development stages were identified using ANOVA followed by Tukey's test. Hierarchical clustering of the differentially expressed lipid species was performed using Euclidean distances and Ward linkage to show relationship between samples and features.

\section{Results}

\subsection{Cytoplasmic lipid droplets content}

The cytoplasmic lipid droplets were homogenously distributed in the cytoplasm of oocyte and early embryos (Fig. 1A). There were a culture media and a culture media by development stage interaction effects $(P<0.05)$. Lipid content increased $(\mathrm{P}<0.05)$ at morula stage compared with other stages, followed by a decrease $(\mathrm{P}<0.05)$ at blastocyst stage in both culture media (Fig. 1B). The impact of the culture media was observed only at the morula and blastocyst stages, in which SOFaaci medium caused an increase $(\mathrm{P}<0.05)$ in the cytoplasmic lipid content compared with SOF-BE1 (Fig. 1B).

Immature oocytes presented similar lipid content level $(\mathrm{P}>0.05)$ compared with embryos of two-cell and eight- to 16-cell stages cultured in both SOFaaci- and SOF-BE1 media. However, lipid content was reduced $(\mathrm{P}<0.05)$ in SOF-BE1-derived blastocysts compared with oocytes and two-cell and eight- to 16-cell stages (Fig. 1B). SOFaaciderived blastocysts had lower $(\mathrm{P}<0.05)$ cytoplasmic lipids compared with SOFaaci-derived eight- to 16-cell embryos. Although there were a culture media and culture media by development stage interaction effects $(\mathrm{P}<0.05)$ on cytoplasmic lipid droplets content evaluation (Fig. 1B), no remarkable culture media and culture media by developmental stage interaction effects $(P>0.05)$ were identified in lipid profile and transcript-level evaluations; therefore, data were combined for all further analysis and only development stage results are presented.

Additionally, we have also analyzed the cytoplasmic lipid droplet content corrected by the median cell number of each development stage [42]: two cells (two-cell embryos' lipid content FI divided per two), eight to 16 cells (eight- to 


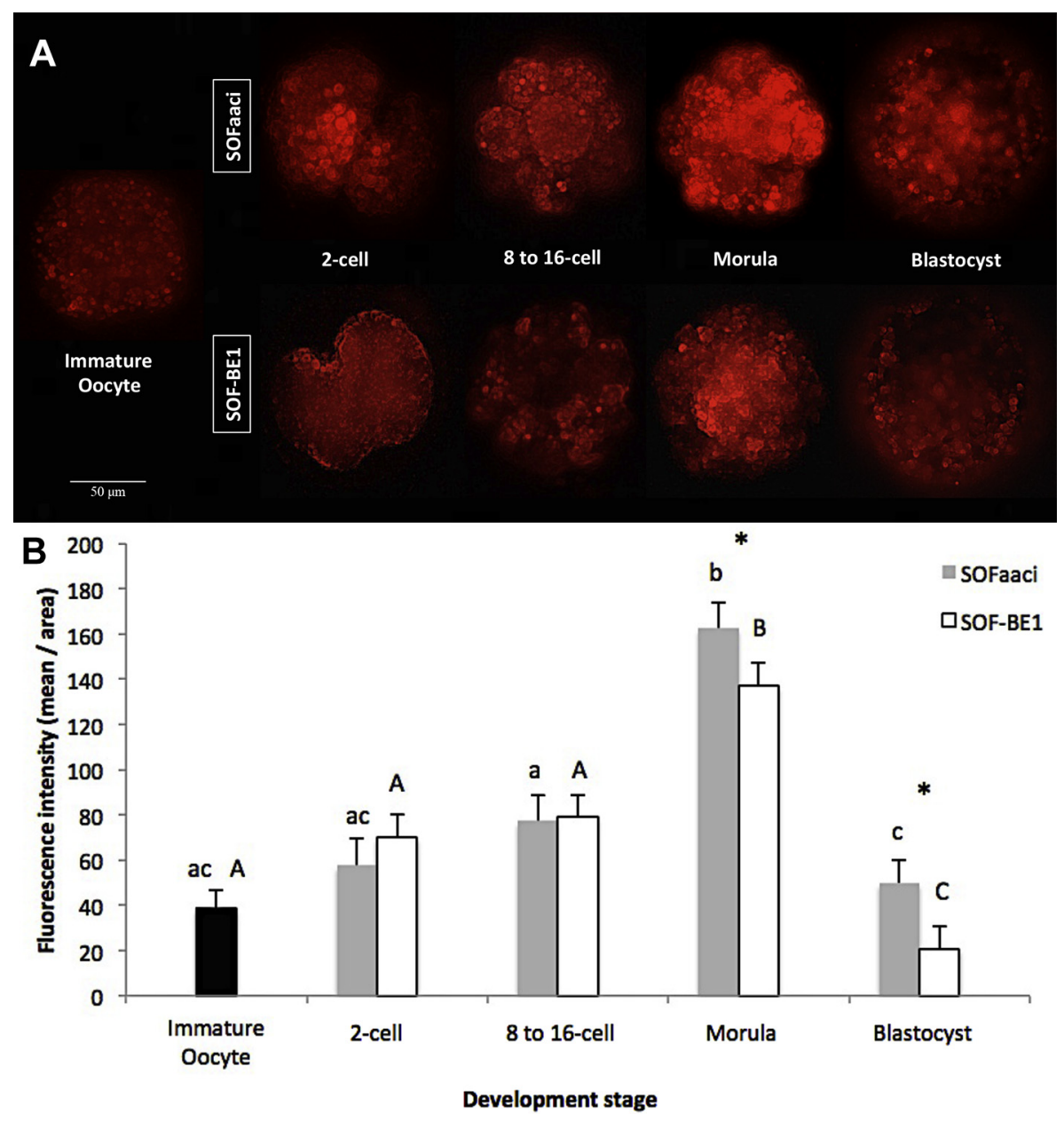

Fig. 1. (A) Representative images of cytoplasmic lipid droplets labeled with Nile Red at immature oocyte, and two-cell, eight- to 16-cell embryos, morula, and blastocyst stages of development cultured in SOFaaci or SOF-BE1 media. (B) Stage-specific lipid content during early bovine embryo development expressed by mean fluorescence intensity per area (least-squares mean \pm SEM). Values without common lowercase (within SOFaaci group) or uppercase (within SOF-BE1 group) letters differ significantly ( $\mathrm{P}<0.05 ; \mathrm{n}=5-9$ per group) throughout embryo development compared with the immature oocyte. Asterisks $\left({ }^{*}\right)$ represent significant differences $(\mathrm{P}<0.05)$ between SOFaaci and SOF-BE1 media within development stage. SOFaaci, modified synthetic oviduct fluid; SOF-BE1, synthetic oviduct fluid-bovine embryo 1. (For interpretation of the references to color in this Figure, the reader is referred to the web version of this article.)

16-cell embryos' lipid content FI divided per 12), morula (morula's lipid content FI divided per 48), and blastocyst (blastocyst's lipid content FI divided per 132). Cytoplasmic lipid droplet content was increased $(\mathrm{P}<0.05)$ at immature oocytes (58.4 $\pm 3.5^{\mathrm{aA}}$; lowercase and uppercase letters compared with SOFaaci and SOF-BE1 derived embryos, respectively) compared with other stages produced using SOFaaci $\left(28.8 \pm 4.1^{\mathrm{b}}, 6.4 \pm 3.8^{\mathrm{c}}, 3.4 \pm 3.8^{\mathrm{c}}, 0.4 \pm 4.4^{\mathrm{c}}\right.$; respectively for two-cell embryos, eight- to 16-cell embryos, morula, and blastocyst stage) and SOF-BE1 (35.0 $\pm 4.5^{\mathrm{B}}$, $6.6 \pm 4.1^{C}, 2.9 \pm 3.3^{C}, 0.2 \pm 4.4^{C}$, respectively, for two-cell embryos, eight-to 16-cell embryos, morula, and blastocyst stage). Two-cell embryos had more $(\mathrm{P}<0.05)$ lipid droplets content than eight- to 16-cell embryos, morula, and blastocyst. There was no difference $(\mathrm{P}>0.05)$ in the lipid content among eight- to 16-cell embryos, morula, and blastocyst. Moreover, the lipid content of SOFaaci and SOF-BE1-derived embryos were not different $(\mathrm{P}>0.05)$. How the cytoplasmic lipid content of role embryos (data not corrected by the cell number) were close related with mRNA levels of lipid metabolism-related genes and agrees with the literature that serum-containing media increase embryo lipid content [14,20,43], it was decided to considerate these results for the data interpretation and comprehensive lipid analysis during early embryo development.

\subsection{Stage-specific MALDI-MS lipid signatures in early bovine embryo development}

No remarkable culture media and culture media by developmental stage interaction effects $(P>0.05)$ were identified in lipid profile; therefore, data were combined for all further analysis and only development stage results are presented. PL and TAG structures are named by the lipid class abbreviation (PC, PE, SM, and TAG) followed by the total number of carbons and double bonds attached to the glycerol backbone and separated by a colon. Lipid structures were attributed on the basis of LIFT data (described 

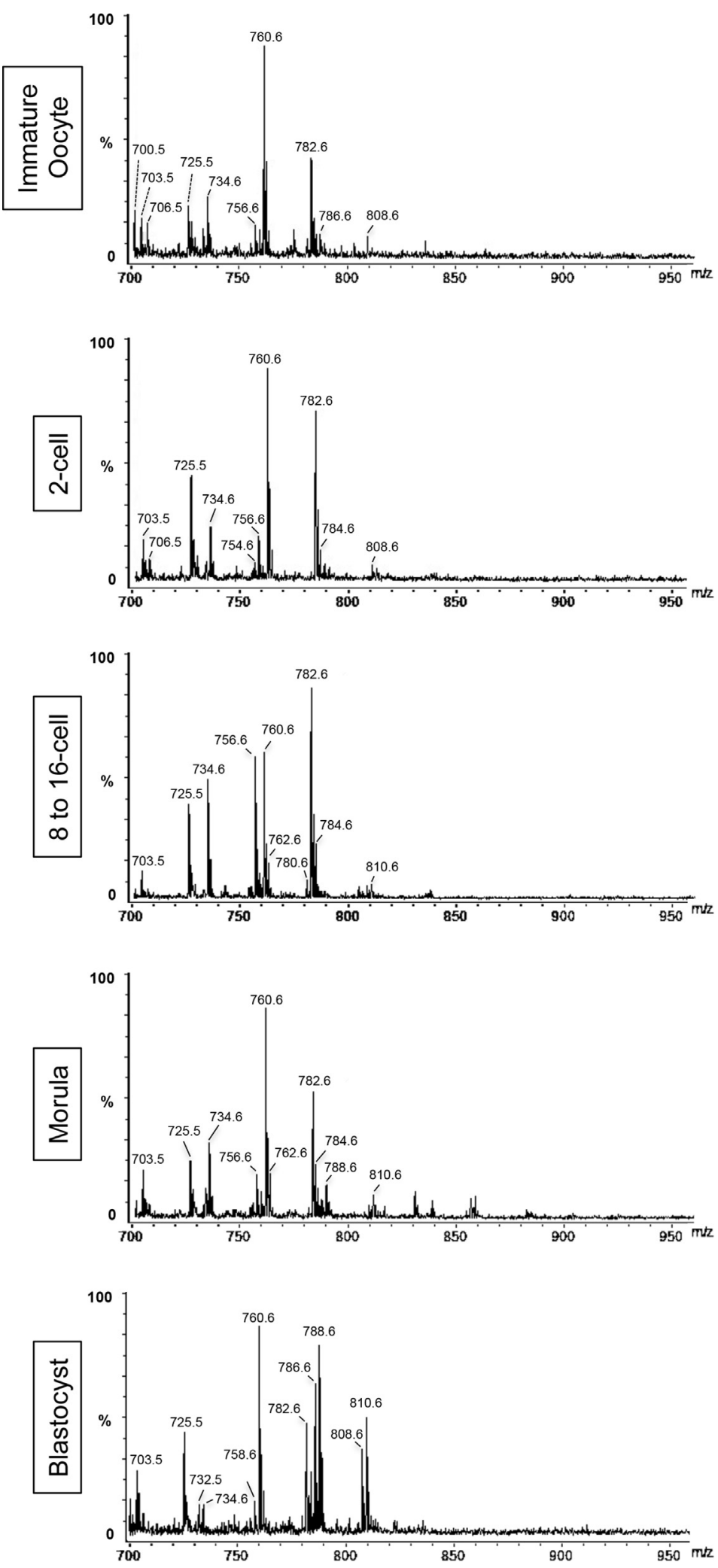

Fig. 2. Representative MALDI-MS in the positive ion mode for stage-specific lipid profiles of immature oocytes $(\mathrm{n}=6)$ and in vitro-produced embryos $(\mathrm{n}=11$ 17); the intensity presented is relative to the most intense ion pick, and each pick represents one phospholipid. 
subsequently), previous MALDI-MS lipid profile studies $[21,22,30,37,38]$, and through consulting two lipid databases (http://lipidsearch.jp or www.lipidmaps.org). Figure 2 displays a representative lipid profile of each development stage. Note that a mixture of isomers is frequently observed for a single lipid ion.

PLS-DA analysis shows that early embryo development stages can be resolved through their MALDI-MS profiles by group clustering in the two-dimensional PLS-DA score plots (Fig. 3A). Slight overlaps between immature oocytes, and embryos of two-cell and eight- to 16-cell stages can be observed (Fig. 3A).

For the three-dimensional PLS-DA plot, however, early embryo development stages were separated, with even more pronounced group individualization and greater deviation starting at eight- to 16-cell stage and advancing to morula and blastocyst stages (Fig. 3B). Supplementary Table 1 lists the discriminated significant lipids from early development stages as indicated by the PLS-DA analysis.

Hierarchical clustering analysis (Supplementary Fig. 1) of the acquired MALDI-MS spectra also suggested that the averaged peak intensities extracted from each set data are well separated and distinguishable between early embryo development stages. These data also allow following the fluctuations of each lipid species during embryo development and, in combination with the differentially expressed lipid species (Fig. 4), suggests putative biomarker peaks for dynamic lipid changes during early bovine embryo development.

Differentially abundant lipid species between immature oocytes and early embryo development stages were identified (Fig. 4). Only significant changes in the lipid profiles during embryo development were annotated.

In immature oocytes, the relative abundance of protonated PC (30:0) and PC (30:3) and sodiated PE (38:5) were increased $(\mathrm{P}<0.05)$ compared with other development stages (Fig. 4; please find in Supplementary Table 1 each lipid assignment and its respective $m / z$ ). In contrast, the relative abundances of protonated SM (16:0), PCe
(32:0), PC (36:2), PC (36:1), sodiated SM (16:0), protonated PC (38:5) and/or sodiated PC (36:2), and protonated PC (38:4) and/or sodiated PC $(36: 1)$ were reduced $(\mathrm{P}<0.05)$ in immature oocytes compared with blastocysts (Fig. 4).

The sodiated PC (32:1) and/or PC (34:4) and protonated PC (30:0) were overexpressed $(\mathrm{P}<0.05)$ in two-cell embryos compared with other development stages (Fig. 4). Nonetheless, the protonated PE (38:5) levels started to drop at two-cell stage and remained low until the blastocyst stage (Fig. 4).

At the eight- to 16-cell stage, protonated PC (32:0) and PC (34:2), sodiated PC (32:0), and sodiated PC (34:2) and/or protonated $\mathrm{PC}(36: 5)$ presented a greater $(\mathrm{P}<0.05)$ relative abundance compared with other stages, whereas the relative intensity of protonated PC (30:0) started to drop at eight- to 16-cell stage and remained low until blastocyst stage (Fig. 4).

At the morula stage, the relative abundances of the protonated and sodiated SM $(16: 0)$ started to increase $(\mathrm{P}<0.05)$, whereas the protonated and sodiated PC (32:0) levels were increased $(\mathrm{P}<0.05)$ at this developmental stage (Fig. 4).

Finally, seven lipids were remarkably more abundant $(\mathrm{P}<0.05)$ at the blastocyst compared with the other stages (protonated SM [16:0], PCe [32:0], PC [36:2], PC [36:1]; sodiated [SM, 16:0]; and protonated PC [38:5] and/or sodiated PC [36:2]; and protonated PC [38:4] and/or sodiated PC [36:1]; Fig. 4). The protonated and sodiated PC (32:0) were less abundant $(P<0.05)$ in blastocysts compared with morula and eight- to 16-cell embryos (Fig. 4), whereas the relative intensity of protonated PC (30:0) was reduced $(\mathrm{P}<0.05)$ at blastocyst stage compared with immature oocyte and two-cell stage (Fig. 4).

\subsection{MS/MS characterization of PLs in immature oocytes and embryos}

To confirm the structural attributions for lipids on the basis of the literature and database search, lipid ions were subjected to MS/MS via the LIFT-MS technique [44]. The
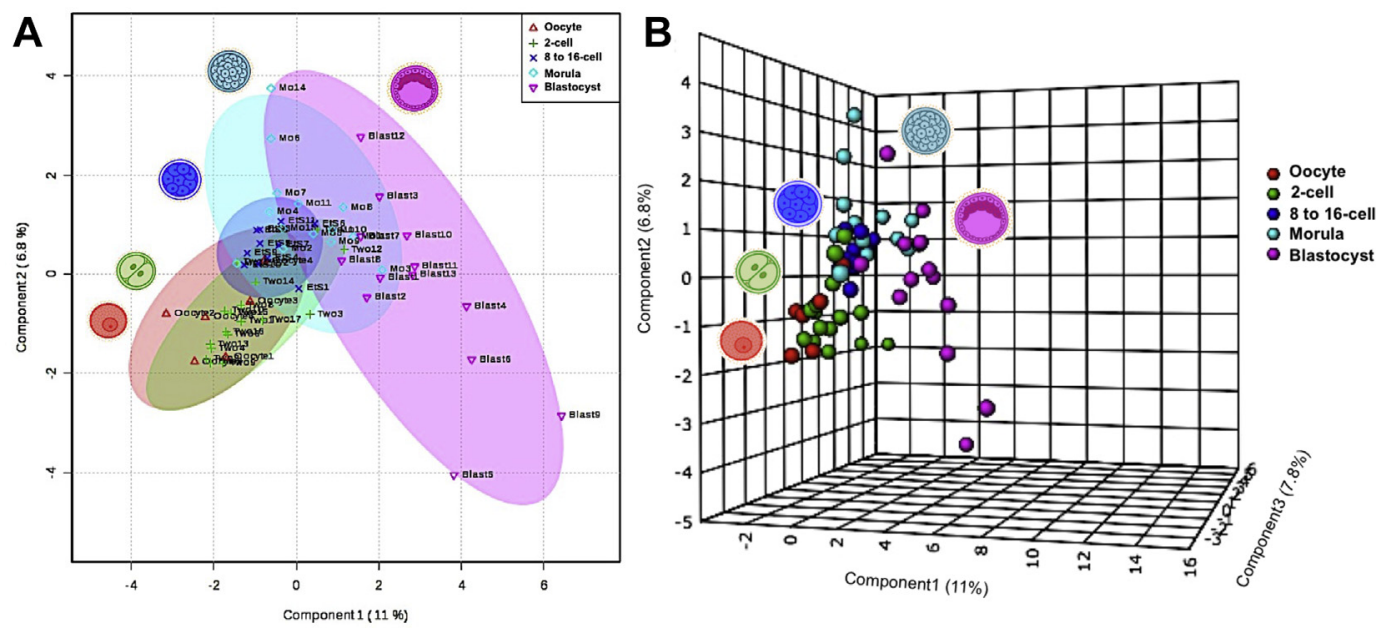

Fig. 3. Two-dimensional (A) and three-dimensional (B) partial least-squares discriminant analysis plots from MALDI-MS data of stage-specific lipid profiles of in vitro-produced bovine embryos; $\mathrm{n}=6$ to 17 per group. 

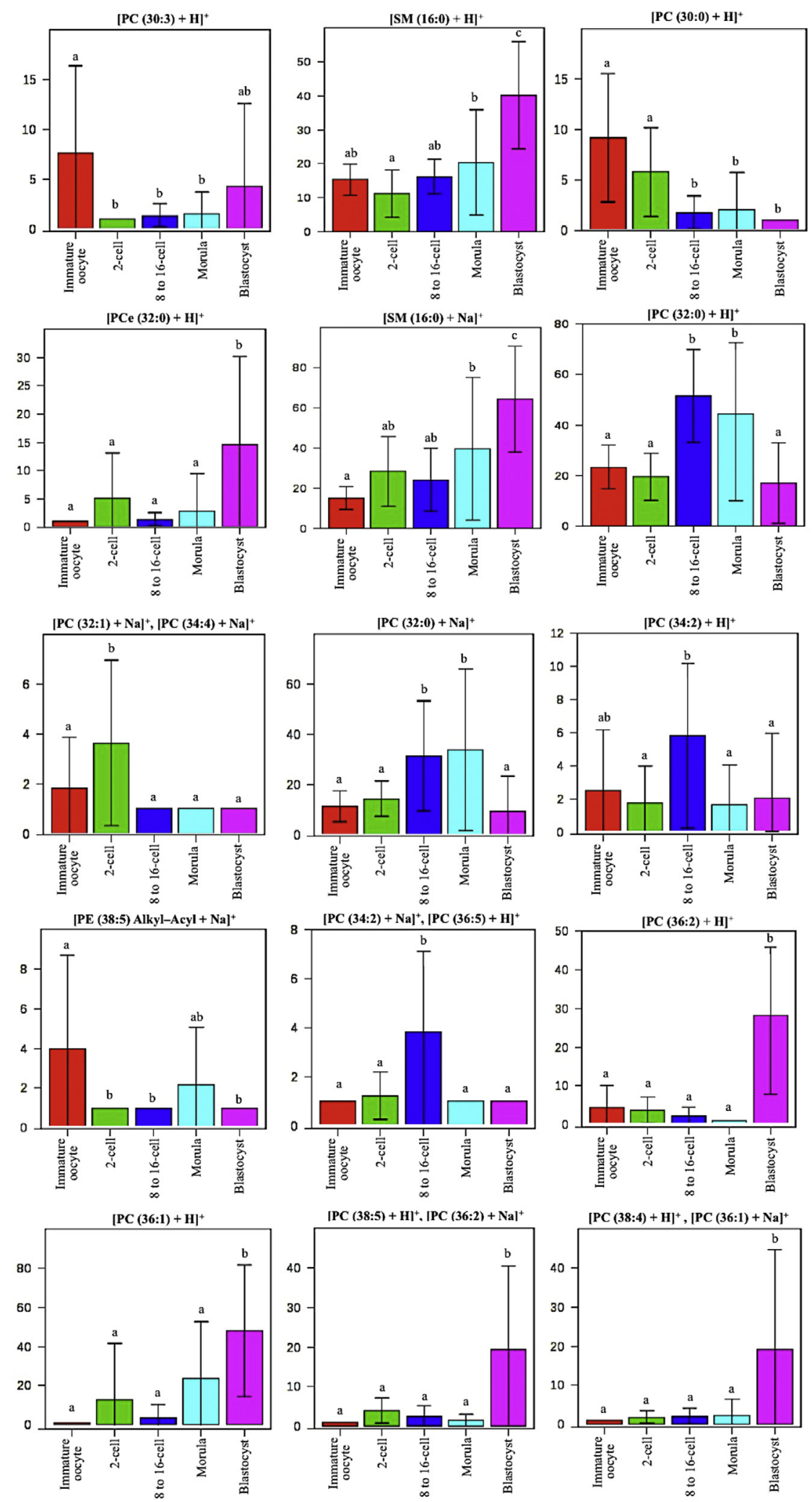

Fig. 4. Relative intensities of differentially expressed phospholipids of stage-specific in vitro-produced bovine embryos. PC, phosphatidylcholines; PC with a lower case $e$ refer to plasmanyl subspecies; PE, phosphatidylethanolamine; SM, sphingomyelins; $\mathrm{n}=6$ to 17 per group. 
MS/MS fragmentation of lipid ions can provide class structural attributions. Our MS/MS results were compatible with those reported in previous studies [21,22,30,37,38,45]. The loss of a neutral of 59 Da corresponds to neutral trimethyl amine $\left[\mathrm{N}\left(\mathrm{CH}_{3}\right)_{3}\right]$, whereas loss of $124 \mathrm{Da}$ is related to the cyclophosphane ring $\left(\mathrm{C}_{2} \mathrm{H}_{5} \mathrm{O}_{4} \mathrm{P}\right)$. The fragment ion of $\mathrm{m} / \mathrm{z} 147$ corresponds to sodiated cyclophosphane and that of $\mathrm{m} / \mathrm{z} 184$ to monoprotonated dihydrogen phosphate choline $\left(\mathrm{C}_{5} \mathrm{H}_{15} \mathrm{PO}_{4} \mathrm{~N}\right)$ (Supplementary Fig. 2).

\subsection{Relative abundance of mRNA transcripts for ACSL3,} ELOVL5, and ELOVL6 in early bovine embryo development

No remarkable culture media and culture media by developmental stage interaction effects $(P>0.05)$ were identified in transcript-level evaluations. Therefore, data were combined for all further analysis and only development stage results are presented. Levels of mRNA of target genes related with metabolic pathways that activate fatty acids, synthesize complex lipids, and elongate fatty acids (ACSL3, ELOVL5, and ELOVL6) were evaluated to gain further insight into lipid metabolism. Relative ACSL3, ELOVL5, and ELOVL6 mRNA abundances increased $(\mathrm{P}<0.05)$ at morula stage compared with other stages, followed by a decrease $(\mathrm{P}<0.05)$ at blastocyst stage (Fig. 5).

ACSL3 mRNA level was, however, reduced $(\mathrm{P}<0.05)$ in blastocysts compared with oocytes, two-cell embryos, eightto 16-cell embryos, and morula stages (Fig. 5), whereas mRNA relative abundance of ELOVL5 was reduced $(\mathrm{P}<0.05)$ in blastocysts compared with two-cell, eight- to 16-cell, and morula stages (Fig. 5). ELOVL6 mRNA level was only reduced in blastocysts compared with morula stage. Other comparisons between different development stages of each target genes mRNA level were not different $(\mathrm{P}>0.05)$.

\subsection{Comprehensive lipid analysis during early bovine embryo development}

Lipid profiles started to deviate with the increased abundances of specific membrane lipid species (protonated

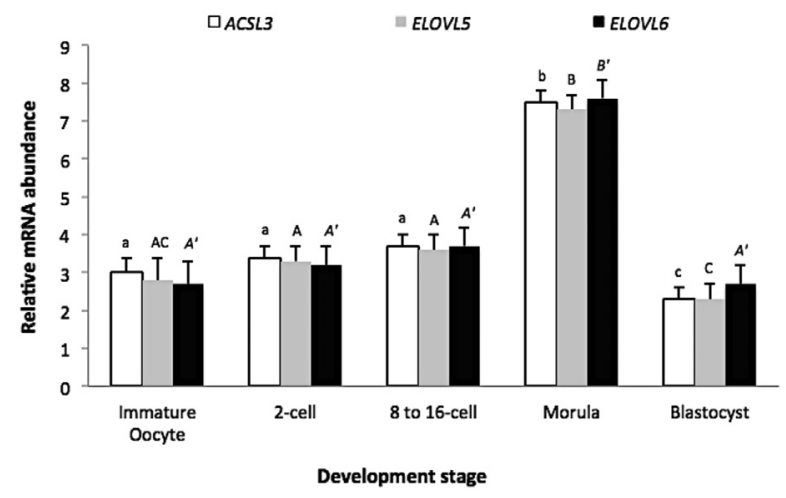

Fig. 5. Stage-specific relative abundance of mRNA transcripts for ACSL3, ELOVL5, and ELOVL6 during early bovine embryo development (least-squares mean \pm SEM). Values without common lowercase (within ACSL3), uppercase (within ELOVL5), and in italic accent uppercase (within ELOVL6) letters differ significantly ( $\mathrm{P}<0.05 ; \mathrm{n}=4-8$ per group) throughout embryo development compared with the immature oocyte.
PC [32:0] and PC [34:2], sodiated PC [32:0], and protonated PC [36:5] and/or sodiated PC [34:2]) in eight- to 16-cell embryos (Table 1).

Basal levels of ACSL3 mRNA were presented until eightto 16-cell stage, followed by an increase at morula, and a subsequent drop at blastocyst stage (Table 1). In the same way, relative ACSL3 mRNA level was associated with the cytoplasmic lipid content fluctuation throughout development, presenting a close relationship between lipid droplets accumulation and the relative abundance of mRNA transcript for ACSL3, revealing a putative cytoplasmic lipid accumulation biomarker (Table 1 ).

Relative ELOVL5 and ELOVL6 mRNA abundance increased at morula stage followed by a decrease at blastocyst stage. It is well documented that ELOVLs elongate saturated, monounsaturated, and polyunsaturated fatty acids after ACSL activation. ELOVL5 and ELOVL6 higher expression preceded the increase of a series of lipid species at blastocyst stage containing saturated, monounsaturated, and polyunsaturated elongated fatty acids with 16, 18, and 20 carbons attached to the three-carbon backbone of PL (Table 1), indicating potential markers of embryo PL fatty acid elongation. Furthermore, after ACSL3, ELVOL5, and ELOVL6 expression drop, cytoplasmic lipid content has decreased (Table 1), suggesting that lipid droplets were consumed (i.e., lipid droplets fatty acids were activated by ACSLs) for the synthesis of complex lipids, such as membrane PL containing elongated fatty acids at the blastocyst stage.

In addition, the early embryo lipid profile dynamics revealed putative stage-specific biomarker peaks, independent of environmental conditions (i.e., culture media), which can be readily associated with key stage-dependent biologic process during embryogenesis (Fig. 4, and Table 1), e.g., oocyte maturation and fertilization (immature oocyte

Table 1

Comprehensive results of notable fluctuations in cytoplasmic lipid droplets content, relative mRNA transcripts of ACSL3, ELOVL5, and ELOVL6, and lipid profiles levels in eight- to 16-cell embryos, morula, and blastocyst.

\begin{tabular}{|c|c|c|c|}
\hline $\begin{array}{l}\text { Variable/development } \\
\text { stage }\end{array}$ & $\begin{array}{l}\text { Eight- to 16-cell } \\
\text { embryos }\end{array}$ & Morula & Blastocyst \\
\hline $\begin{array}{l}\text { Cytoplasmic lipid } \\
\text { droplets content }\end{array}$ & Basal & $\uparrow$ & $\downarrow$ \\
\hline \multicolumn{4}{|c|}{ Relative mRNA transcript levels } \\
\hline ACSL3 & Basal & $\uparrow$ & $\downarrow$ \\
\hline ELOVL5 & Basal & $\uparrow$ & $\downarrow$ \\
\hline ELOVL6 & Basal & $\uparrow$ & Basal \\
\hline \multicolumn{4}{|l|}{ MALDI-MS lipid profiles } \\
\hline$[\mathrm{SM}(16: 0)+\mathrm{H}]^{+}$ & Basal & $\uparrow$ & $\uparrow$ \\
\hline$[\mathrm{PCe}(32: 0)+\mathrm{H}]^{+}$ & Basal & Basal & $\uparrow$ \\
\hline$[\mathrm{SM}(16: 0)+\mathrm{Na}]^{+}$ & Basal & $\uparrow$ & $\uparrow$ \\
\hline$[\mathrm{PC}(32: 0)+\mathrm{H}]^{+}$ & $\uparrow$ & $\uparrow$ & Basal \\
\hline$[\mathrm{PC}(32: 0)+\mathrm{Na}]^{+}$ & $\uparrow$ & $\uparrow$ & Basal \\
\hline$[\mathrm{PC}(34: 2)+\mathrm{H}]^{+}$ & $\uparrow$ & Basal & Basal \\
\hline $\begin{array}{l}{[\mathrm{PC}(34: 2)+\mathrm{Na}]^{+},} \\
{[\mathrm{PC}(36: 5)+\mathrm{H}]^{+}}\end{array}$ & $\uparrow$ & Basal & Basal \\
\hline$[\mathrm{PC}(36: 2)+\mathrm{H}]^{+}$ & Basal & Basal & $\uparrow$ \\
\hline$[\mathrm{PC}(36: 1)+\mathrm{H}]^{+}$ & Basal & Basal & $\uparrow$ \\
\hline $\begin{array}{l}{[\mathrm{PC}(38: 5)+\mathrm{H}]^{+}} \\
{[\mathrm{PC}(36: 2)+\mathrm{Na}]^{+}}\end{array}$ & Basal & Basal & $\uparrow$ \\
\hline $\begin{array}{l}{[\mathrm{PC}(38: 4)+\mathrm{H}]^{+}} \\
{[\mathrm{PC}(36: 1)+\mathrm{Na}]^{+}}\end{array}$ & Basal & Basal & $\uparrow$ \\
\hline
\end{tabular}

Arrows indicate elevated $(\uparrow)$ or reduced $(\downarrow)$ relative abundance levels in relation to the other group. Basal level was defined as the most common abundance value between groups. 
PL variations; protonated PC [30:0] and PC [30:3], sodiated PE [38:5]); fertilization and cleavage (two-cell embryo PL variations; protonated PC [30:0], and sodiated PC [32:1] and/or PC [34:4]); cleavage and embryonic genome activation (eight- to 16-cell embryo PL variations; protonated PC [32:0] and PC [34:2], sodiated PC [32:0], and sodiated PC [34:2] and/or protonated PC [36:5]); compaction and blastocyst formation (morula PL variations; protonated and sodiated SM [16:0] and PC [32:0]); and differentiation, blastocoel formation and expansion, and hatching (blastocyst PL variations; protonated SM [16:0], PCe [32:0], PC [36:2], PC [36:1], sodiated SM [16:0], protonated PC [38:5] and/or sodiated PC [36:2], and protonated PC [38:4] and/or sodiated PC [36:1]).

\section{Discussion}

We provide a comprehensive lipid analysis of membrane PL dynamics during early bovine embryo development in a high-throughput manner association through mass spectrometry, cytoplasmic lipid droplets content, and target qPCR transcripts monitoring. The amount of cytoplasmic lipid droplets increased at morula followed by a decreased at blastocyst stage during preimplantation period that was closely related with the ACSL3 mRNA levels. Significant differences in the lipid profiles according to the developmental stage of in vitro-produced bovine embryos were identified, sustaining that PL undergoes dynamic changes during embryonic development, which can be associated with key biologic process during embryogenesis. Increased ELOVL5 and ELOVL6 mRNA levels at morula stage preceded an increased abundance of membrane PL containing elongated saturated, monounsaturated, and polyunsaturated fatty acids with 16,18 , and 20 carbons at blastocyst stage.

A series of studies have described the composition, in terms of fatty acids, TAG and lipid droplets content, oocytes, and embryos of many species [14,16,29]. Structural and composition changes in the lipid profiles throughout development and their potential relationship with cellular and molecular mechanisms governing mammalian embryo preimplantation development are, however, still poorly understood.

Somatic cells take up free fatty acids that are esterified and stored in lipid droplets mainly as TAG [46]. A major biologic function of these lipids is the storage of metabolic energy $[16,17]$. In the present work, lipid droplets were found to be homogeneously distributed in immature oocyte/embryo cells, agreeing with previous descriptions $[16,22]$. The amount of cytoplasmic lipid droplets increased at morula stage concomitant with the raise of ACSL3 mRNA levels. It seems that there is a combination of fat accumulation and genome activation, which may start to take place at the eight- to 16-cell stage (for a review, see Sirard [47]).

It has already been described that lipid droplet levels decrease during embryo development [48-50]. Indeed, lipid content was found to drop at blastocyst stage. A possible hypothesis to the decrease in overall fat content during blastulation is their consumption, mainly by trophoblastic cells, via ß-oxidation [16,22], to support an increased energy demand during blastocyst formation, expansion of the blastocoel, and hatching [16,51].
However, we cannot oversimplify the role of TAG when only considering them as an energy source. It may be fair to propose the initial role of TAG in cellular metabolism as a precursor for the synthesis of PL [52]. Indeed, we have observed a great number of overexpressed PL lipid species at blastocyst stage, which is corroborated by the reduction of cytoplasmic lipid droplets content and greater membrane lipid demand synthesis at this stage to allow an active increase in embryo cell number. An interesting observation is the occurrence of these events after the overexpression of transcripts coding for the fatty acid activation- and elongation-associated enzymes (ACSL3, ELOVL5, and ELOVL6) at morula stage, which could be linked to the activation of lipid droplets fatty acids in preparation for the synthesis of complex lipids, such as PL membranecontaining elongated fatty acids (Table 1).

The influence of different culture environmental conditions was only observed when cytoplasmic lipid droplets were assessed, at morula and blastocyst stages, in which SOFaaci medium increased cytoplasmic lipid droplets content compared with SOF-BE1. In the present experiment, two SOF-based media for embryo culture, a classical one (SOFaaci [33]), commonly used worldwide and supplemented with fetal calf serum, and an SOF-based medium (SOF-BE1 [34]), with a formulation that allows the absence of fetal calf serum supplementation that is recognized by its detrimental impact in the embryo lipid content and cryosurvival, was used [20,43]. Despite the similarity between these two SOF-based culture media, they have some major differences in their composition including the absence of FCS, increased concentration of glutamine $(5 \times)$, pyruvate $(2 \times)$, and essential and nonessential amino acids (2.25 and $2 \times$, respectively) in SOF-BE1 compared with SOFaaci. May be, this increased lipid content observed in the SOFaaci-derived embryos is associated with the increased mRNA levels of ACSL3, after genome activation, that favors serum's fatty uptake by embryo cells, as observed previously in human placental trophoblast cells [26]. The exact mechanism regulating the accumulation of cytoplasmic lipid droplets in oocytes/embryos is still unknown. It is, however, well documented that FCS media culture supplementation increases embryo lipid content [20].

As already described, lipid droplets or endoplasmic reticulum membranes present great abundance of ACLS3 protein [53]. ACSL3 isoform has a highest affinity for its preferred substrates: laurate (C12:0), myristate (C14:0), arachidonate (C20:4), and eicosapentaenoic acid (C20:5) [54]. In addition, each ELOVL enzyme isoform also has its substrate preference, e.g., ELOVL5 elongates palmitoleic (C16:1), oleic (C18:1), linolenic (C18:3), stearidonic (C18:4), arachidonic (C20:4), and eicosapentanoic (C20:5) acids [27]; and ELOVL6 elongates long chain-saturated (palmitic acid; C16:0) and monounsaturated (palmitoleic acid; C16:1) fatty acids [28]. These long chain fatty acids are key components of membrane PL [27].

Cells and intracellular compartments are separated from their environment by membranes. Biologic membranes vary regarding the associated proteins and their lipid composition. Thousands of lipid molecules have already been described in the lipidome of cellular membranes, each with 
its own specific properties indicating that lipids do not only work simply as passive structural membrane components [55]. Understanding the lipid profile of membranes is important to address the mechanisms governing mammalian preimplantation development. Changes in the lipid structural composition of the membranes can be readily detected by mass spectrometry [22].

MALDI-MS has proved to be a powerful tool in lipidomics [56], generating PL (mainly PC, PE, and SM in the positive ion mode) and TAG profiles with simple sample manipulation and data interpretation. Through MALDI-MS, several major PL were identified for each experimental group. As expected, some overlaps were observed between oocytes and embryo development stages, especially during the first cleavage stages (immature oocyte and embryos at the two-cell and eight- to 16-cell stages), whereas with the progression of development, greater deviation starts at eight- to 16-cell stage and advances to morula and blastocyst stages. The shift in membrane lipid profile observed at the eight- to 16-cell stage could be related to the acquisition of regulatory molecules of fat metabolism, after embryonic genome activation, which resulted in lipid profile differences at morula and blastocyst stage due to lipid membrane remodeling and specialization, sustained by the variations of mRNA levels of lipid metabolism-associated genes (ACSL3, ELOVL5, and ELOVL6). Potentially, this specific period could be an eligible moment for functional experiments to modulate embryo lipid metabolism to favor or inhibit some specific lipid species.

Confirming the hypothesis of lipid membrane fluctuation throughout embryo development, the number of carbons, fatty acid saturation, and class composition for the PL are actively varying. Phospholipids were found, therefore, to undergo pronounced dynamic structural changes during embryonic development. Our study was focused on the characterization of PL, but significant variations in TAG profiles were also identified.

Remarkable changes in numerous lipid species were observed at immature oocytes and preimplantation embryos. Note that all these observed differences were independent of culture media, which further validates the relevance of the identified molecules regardless environmental conditions during early embryo development. The early embryo lipid profile dynamics revealed putative biomarker peaks for lipid stage-specific induced changes which can be readily associated with key biological process related with important events during in vitro and in vivo embryogenesis period (e.g., oocyte maturation, fertilization, cleavage, embryonic genome activation, compaction, differentiation, blastocoel formation and expansion, and hatching). Whether these specific changes in membrane PL profiles are involved with each embryo biologic processes shall make for interesting functional studies. We have to be cautious to extrapolate all these findings for in vivo retrieved embryos because of the differences between cultures systems that is reflected to lipid profiles peculiarities between in vitro- and in vivo-produced embryos [22]. Commonly the IVP methodologies use culture conditions where embryos grow in medium with oil overlay inside incubators instead of the interior of oviduct and uterus. Further investigation is required to determine whether these differentially expressed PL species are truly involved in each event of embryogenesis period.

Previous studies have described variations in lipid species of oocytes/embryos undergoing vitrification [38,57], mass spectrometry imaging [7], cultured under different protein source and atmospheric conditions [21], between different subspecies [22], and between in vivo- and in vitroderived embryos $[8,22]$.

In the present work, we have observed variations of unsaturation degree of PL fatty acyl residues, fatty acyl chain length, and differences in PL class composition. Additionally, ELOVL5 and ELOVL6 overexpression preceded an increased abundance of a series of lipid species at blastocyst stage containing saturated, monounsaturated, and polyunsaturated elongated fatty acids with 16,18 , and 20 carbons attached to the three-carbon backbone of PL.

In conclusion, this study reports characteristic lipidome signatures of a comprehensive lipid analysis involving cytoplasmic lipid droplets staining, membrane PL's mass spectrometry evaluation, and qPCR lipid metabolismrelated genes monitoring of immature oocytes and preimplantation embryos. Our results suggested that the cytoplasmic lipid droplets content and mRNA transcript levels of ACSL3, ELOVL5, and ELOVL6 in immature oocytes and preimplantation embryos are associated with the chemical structure of their membrane lipids, discriminating dynamic changes during early embryonic development. The data presented here represents an initial step to assess the role of specific lipid species in important events of embryogenesis and identified some putative lipid metabolism biomarkers for cytoplasmic lipid droplets content (ACSL3 expression) and fatty acid elongation (ELOVL5 and ELOVL6 expression) in bovine embryos.

\section{Acknowledgments}

This research was supported by Conselho Nacional de Desenvolvimento Científico e Tecnológico-CNPq, Brasil (grant 446647/2014-4; fellowships 162598/2013-0 and 167908/2013-8) and Fundação de Amparo à Pesquisa do Estado de São Paulo-FAPESP (fellowships 2011/06191-7 and 2012/07206-0). Author contributions: MJS and FDCLA conceived and designed the experiments; TDSR, AT, KRAB, and VGS performed the experiments; MJS and RSV analyzed the data; FDCLA, MJS, JPA, and MNE contributed reagents/materials/analysis tool; and MJS, FSM, and CRF wrote the article.

\section{Appendix A. Supplementary data}

Supplementary data associated with this article can be found, in the online version, at http://dx.doi.org/10.1016/ j.theriogenology.2016.03.025.

\section{References}

[1] Deutsch DR, Fröhlich T, Otte KA, Beck A, Habermann FA, Wolf E, et al. Stage-specific proteome signatures in early bovine embryo development. J Proteome Res 2014;13:4363-76.

[2] Dean W, Santos F, Reik W. Epigenetic reprogramming in early mammalian development and following somatic nuclear transfer. Semin Cell Dev Biol 2003;14:93-100. 
[3] Jiang Z, Sun J, Dong H, Luo O, Zheng X, Obergfell C, et al. Transcriptional profiles of bovine in vivo pre-implantation development. BMC Genomics 2014;15:756.

[4] Graf A, Krebs S, Zakhartchenko V, Schwalb B, Blum H, Wolf E. Fine mapping of genome activation in bovine embryos by RNA sequencing. Proc Natl Acad Sci U S A 2014;111:4139-44.

[5] Demant M, Deutsch DR, Fröhlich T, Wolf E, Arnold GJ. Proteome analysis of early lineage specification in bovine embryos. Proteomics 2015;15:688-701.

[6] Ferreira CR, Pirro V, Eberlin LS, Hallett JE, Cooks RG. Developmental phases of individual mouse preimplantation embryos characterized by lipid signatures using desorption electrospray ionization mass spectrometry. Anal Bioanal Chem 2012;404:2915-26.

[7] Gonçalves RF, Ferreira MS, de Oliveira DN, Canevarolo R, Achilles MA, D'Ercole DL, et al. Analysis and characterisation of bovine oocyte and embryo biomarkers by matrix-assisted desorption ionisation mass spectrometry imaging. Reprod Fertil Dev 2014:28:293-301.

[8] Gonzalez-Serrano AF, Pirro V, Ferreira CR, Oliveri P, Eberlin LS, Heinzmann J, et al. Desorption electrospray ionization mass spectrometry reveals lipid metabolism of individual oocytes and embryos. PLoS One 2013;8:e74981.

[9] Di Paolo G, De Camilli P. Phosphoinositides in cell regulation and membrane dynamics. Nature 2006;443:651-7.

[10] Katso R, Okkenhaug K, Ahmadi K, White S, Timms J, Waterfield MD. Cellular function of phosphoinositide 3-kinases: implications for development, homeostasis, and cancer. Annu Rev Cell Dev Biol 2001; 17:615-75.

[11] Cantley LC. The phosphoinositide 3-kinase pathway. Science 2002; 296:1655-7.

[12] Ye X, Hama K, Contos JJ, Anliker B, Inoue A, Skinner MK, et al. LPA3mediated lysophosphatidic acid signalling in embryo implantation and spacing. Nature 2005;435:104-8.

[13] Burnum KE, Cornett DS, Puolitaival SM, Milne SB, Myers DS, Tranguch S, et al. Spatial and temporal alterations of phospholipids determined by mass spectrometry during mouse embryo implantation. J Lipid Res 2009;50:2290-8.

[14] Ferguson EM, Leese HJ. Triglyceride content of bovine oocytes and early embryos. J Reprod Fertil 1999;116:373-8.

[15] McKeegan PJ, Sturmey RG. The role of fatty acids in oocyte and early embryo development. Reprod Fertil Dev 2011;24:59-67.

[16] Sturmey RG, Reis A, Leese HJ, McEvoy TG. Role of fatty acids in energy provision during oocyte maturation and early embryo development. Reprod Domest Anim 2009;44(Suppl. 3):50-8.

[17] Ferguson EM, Leese HJ. A potential role for triglyceride as an energy source during bovine oocyte maturation and early embryo development. Mol Reprod Dev 2006;73:1195-201.

[18] van Meer G, Voelker DR, Feigenson GW. Membrane lipids: where they are and how they behave. Nat Rev Mol Cell Biol 2008;9:112-24.

[19] Edidin M. Lipids on the frontier: a century of cell-membrane bilayers. Nat Rev Mol Cell Biol 2003;4:414-8.

[20] Sudano MJ, Paschoal DM, Rascado TD, Magalhaes LCO, Crocomo LF, de Lima-Neto JF, et al. Lipid content and apoptosis of in vitro-produced bovine embryos as determinants of susceptibility to vitrification. Theriogenology 2011;75:1211-20.

[21] Ferreira CR, Saraiva SA, Catharino RR, Garcia JS, Gozzo FC, Sanvido GB, et al. Single embryo and oocyte lipid fingerprinting by mass spectrometry. J Lipid Res 2010;51:1218-27.

[22] Sudano MJ, Santos VG, Tata A, Ferreira CR, Paschoal DM, Machado R, et al. Phosphatidylcholine and sphingomyelin profiles vary in Bos taurus indicus and Bos taurus taurus in vitro- and in vivo-produced blastocysts. Biol Reprod 2012:87:130.

[23] Sudano MJ, Caixeta ES, Paschoal DM, Martins Jr A, Machado R, Buratini J, et al. Cryotolerance and global gene-expression patterns of Bos taurus indicus and Bos taurus taurus in vitro- and in vivoproduced blastocysts. Reprod Fertil Dev 2014;26:1129-41.

[24] Yao H, Ye J. Long chain Acyl-CoA synthetase 3-mediated phosphatidylcholine synthesis is required for assembly of very low density lipoproteins in human hepatoma Huh7 cells. J Biol Chem 2008;283: 849-54.

[25] Fujimoto Y, Itabe H, Kinoshita T, Homma KJ, Onoduka J, Mori M, et al. Involvement of ACSL in local synthesis of neutral lipids in cytoplasmic lipid droplets in human hepatocyte HuH7. J Lipid Res 2007;48:1280-92

[26] Weedon-Fekjaer MS, Dalen KT, Solaas K, Staff AC, Duttaroy AK, Nebb HI. Activation of LXR increases acyl-CoA synthetase activity through direct regulation of ACSL3 in human placental trophoblast cells. J Lipid Res 2010;51:1886-96.

[27] Moon Y-A, Hammer RE, Horton JD. Deletion of ELOVL5 leads to fatty liver through activation of SREBP-1c in mice. J Lipid Res 2009;50:412-23.
[28] Wang Y, Botolin D, Xu J, Christian B, Mitchell E, Jayaprakasam B, et al. Regulation of hepatic fatty acid elongase and desaturase expression in diabetes and obesity. J Lipid Res 2006;47:2028-41.

[29] Sata R, Tsujii H, Abe H, Yamashita S, Hoshi H. Fatty acid composition of bovine embryos cultured in serum-free and serum containing medium during early embryonic development. J Reprod Dev 1999;45:97-103.

[30] Tata A, Sudano MJ, Santos VG, Landim-Alvarenga FD, Ferreira CR Eberlin MN. Optimal single-embryo mass spectrometry fingerprinting. J Mass Spectrom 2013:48:844-9.

[31] Sudano MJ, Paschoal DM, da Silva Rascado T, Crocomo LF, Magalhães LC, Junior AM, et al. Crucial surviving aspects for vitrified in vitro-produced bovine embryos. Zygote 2012;22:124-31.

[32] Parrish JJ, Krogenaes A, Susko-Parrish JL. Effect of bovine sperm separation by either swim-up or Percoll method on success of in vitro fertilization and early embryonic development. Theriogenology 1995;44:859-69.

[33] Holm P, Booth PJ, Schmidt MH, Greve T, Callesen H. High bovine blastocyst development in a static in vitro production system using SOFaa medium supplemented with sodium citrate and myoinositol with or without serum-proteins. Theriogenology 1999;52: 683-700.

[34] Fields SD, Hansen PJ, Ealy AD. Fibroblast growth factor requirements for in vitro development of bovine embryos. Theriogenology 2011; $75: 1466-75$.

[35] Genicot G, Leroy JL, Soom AV, Donnay I. The use of a fluorescent dye, Nile red, to evaluate the lipid content of single mammalian oocytes. Theriogenology 2005;63:1181-94.

[36] Barceló-Fimbres M, Seidel GE. Cross-validation of techniques for measuring lipid content of bovine oocytes and blastocysts. Theriogenology 2011;75:434-44.

[37] Milne S, Ivanova P, Forrester J, Alex Brown H. Lipidomics: an analysis of cellular lipids by ESI-MS. Methods 2006;39:92-103.

[38] Jung J, Shin H, Bang S, Mok HJ, Suh CS, Kim KP, et al. Analysis of the phospholipid profile of metaphase II mouse oocytes undergoing vitrification. PLoS One 2014;9:e102620.

[39] Larionov A, Krause A, Miller W. A standard curve based method for relative real time PCR data processing. BMC Bioinformatics 2005;6:62.

[40] Goossens K, Van Poucke M, Van Soom A, Vandesompele J, Van Zeveren A, Peelman LJ. Selection of reference genes for quantitative real-time PCR in bovine preimplantation embryos. BMC Dev Biol 2005;5:27.

[41] Xia J, Mandal R, Sinelnikov IV, Broadhurst D, Wishart DS. MetaboAnalyst 2.0-a comprehensive server for metabolomic data analysis. Nucleic Acids Res 2012;40(Web Server issue):W127-33.

[42] Robertson I, Nelson RE. Certification and identification of the embryo. In: Stringfellow DA, Seidel SM, editors. Manual of the International Embryo Transfer Society. Third edition. Champaign, IL: IETS; 1998. p. 103-16.

[43] Abe H, Yamashita S, Satoh T, Hoshi H. Accumulation of cytoplasmic lipid droplets in bovine embryos and cryotolerance of embryos developed in different culture systems using serum-free or serumcontaining media. Mol Reprod Dev 2002;61:57-66.

[44] Suckau D, Resemann A, Schuerenberg M, Hufnagel P, Franzen J, Holle A. A novel MALDI LIFT-TOF/TOF mass spectrometer for proteomics. Anal Bioanal Chem 2003;376:952-65.

[45] Brügger B, Erben G, Sandhoff R, Wieland FT, Lehmann WD. Quantitative analysis of biological membrane lipids at the low picomole level by nano-electrospray ionization tandem mass spectrometry. Proc Natl Acad Sci U S A 1997;94:2339-44.

[46] Aardema H, Vos PL, Lolicato F, Roelen BA, Knijn HM, Vaandrager AB, et al. Oleic acid prevents detrimental effects of saturated fatty acids on bovine oocyte developmental competence. Biol Reprod 2011;85:62-9.

[47] Sirard MA. Factors affecting oocyte and embryo transcriptomes. Reprod Domest Anim 2012:47(Suppl 4):148-55.

[48] Landim-Alvarenga FC, Bicudo SD. An ultrastructural study of dog embryo. Braz J Morphol Sci 1997;14:213-7.

[49] Romek M, Gajda B, Krzysztofowicz E, Smorag Z. Lipid content of noncultured and cultured pig embryo. Reprod Domest Anim 2009;44:24-32.

[50] Romek M, Gajda B, Krzysztofowicz E, Smorag Z. Changes of lipid composition in non-cultured and cultured porcine embryos. Theriogenology 2010;74:265-76.

[51] Thompson JG, Partridge RJ, Houghton FD, Cox CI, Leese HJ, Oxygen uptake and carbohydrate metabolism by in vitro derived bovine embryos. J Reprod Fertil 1996;106:299-306.

[52] Olukoshi ER, Packter NM. Importance of stored triacylglycerols in streptomyces-possible carbon source far antibiotics. Microbiology (UK) 1994;140:931-43.

[53] Fujimoto Y, Itabe H, Sakai J, Makita M, Noda J, Mori M, et al. Identification of major proteins in the lipid droplet-enriched fraction 
isolated from the human hepatocyte cell line HuH7. Biochim Biophys Acta 2004;1644:47-59.

[54] Fujino T, Kang MJ, Suzuki H, Iijima H, Yamamoto T. Molecular characterization and expression of rat acyl-CoA synthetase 3. J Biol Chem 1996;271:16748-52.

[55] de Kroon AI, Rijken PJ, De Smet CH. Checks and balances in membrane phospholipid class and acyl chain homeostasis, the yeast perspective. Prog Lipid Res 2013;52:374-94.
[56] Schiller J, Süss R, Arnhold J, Fuchs B, Lessig J, Müller M, et al. Matrixassisted laser desorption and ionization time-of-flight (MALDI-TOF) mass spectrometry in lipid and phospholipid research. Prog Lipid Res 2004;43:449-88.

[57] Leão BC, Rocha-Frigoni NA, Cabral EC, Franco MF, Ferreira CR, Eberlin MN, et al. Membrane lipid profile monitored by mass spectrometry detected differences between fresh and vitrified in vitro-produced bovine embryos. Zygote 2015;23:732-41. 
Supplementary Table 1

Significant phospholipids and triglycerides indicated via MALDI-MS of individual early bovine embryos.

\begin{tabular}{|c|c|}
\hline$m / z$ & Lipid ion (carbons:unsaturation) \\
\hline 700.5 & $[\mathrm{PC}(30: 3)]+\mathrm{H}]^{+}$ \\
\hline 703.5 & {$[\mathrm{SM}(16: 0)+\mathrm{H}]^{+}$} \\
\hline 706.5 & {$[\mathrm{PC}(30: 0)+\mathrm{H}]^{+}$} \\
\hline 720.5 & {$[\mathrm{PCe}(32: 0)+\mathrm{H}]^{+}$} \\
\hline 725.5 & {$[\mathrm{SM}(16: 0)+\mathrm{Na}]^{+}$} \\
\hline 727.5 & {$[\mathrm{SM}(\mathrm{d} 34: 0)+\mathrm{Na}]^{+}$} \\
\hline 732.5 & {$[\mathrm{PC}(32: 1)+\mathrm{H}]^{+}$} \\
\hline 734.6 & {$[\mathrm{PC}(32: 0)+\mathrm{H}]^{+}$} \\
\hline 742.6 & {$[\mathrm{PCp}(34: 2)+\mathrm{H}]^{+},[\mathrm{PCe}(34: 3)+\mathrm{H}]^{+}$} \\
\hline 746.6 & {$[\mathrm{PE}(36: 1)+\mathrm{H}]^{+}$} \\
\hline 748.6 & {$[\mathrm{PE}(38: 6) \text { alkenyl-acyl }+\mathrm{H}]^{+}$} \\
\hline 753.6 & {$[\mathrm{SM}(18: 0)+\mathrm{Na}]^{+}$} \\
\hline 754.6 & {$[\mathrm{PC}(32: 1)+\mathrm{Na}]^{+},[\mathrm{PC}(34: 4)+\mathrm{Na}]^{+}$} \\
\hline 756.6 & {$[\mathrm{PC}(32: 0)+\mathrm{Na}]^{+}$} \\
\hline 758.6 & {$[\mathrm{PC}(34: 2)+\mathrm{H}]^{+}$} \\
\hline 760.6 & {$[\mathrm{PC}(34: 1)+\mathrm{H}]^{+}$} \\
\hline 762.6 & {$[\mathrm{PC}(34: 0)+\mathrm{H}]^{+}$} \\
\hline 768.6 & {$[\mathrm{PE}(42: 4)+\mathrm{H}]^{+},[\mathrm{PCp}(36: 3)+\mathrm{H}]^{+}$} \\
\hline 774.6 & {$[\mathrm{PE}(38: 5) \text { alkyl-acyl }+\mathrm{Na}]^{+}$} \\
\hline 780.6 & {$[\mathrm{PC}(34: 2)+\mathrm{Na}]^{+},[\mathrm{PC}(36: 5)+\mathrm{H}]^{+}$} \\
\hline 782.6 & {$[\mathrm{PC}(36: 4)+\mathrm{H}]^{+},[\mathrm{PC}(34: 1)+\mathrm{Na}]^{+}$} \\
\hline 784.6 & {$[\mathrm{PC}(34: 0)+\mathrm{Na}]^{+}$} \\
\hline 786.6 & {$[\mathrm{PC}(36: 2)+\mathrm{H}]^{+}$} \\
\hline 788.6 & {$[\mathrm{PC}(36: 1)+\mathrm{H}]^{+}$} \\
\hline 798.6 & {$[\mathrm{PC}(34: 1)+\mathrm{K}]^{+}$} \\
\hline 808.6 & {$[\mathrm{PC}(38: 5)+\mathrm{H}]^{+},[\mathrm{PC}(36: 2)+\mathrm{Na}]^{+}$} \\
\hline 810.6 & {$[\mathrm{PC}(38: 4)+\mathrm{H}]^{+},[\mathrm{PC}(36: 1)+\mathrm{Na}]^{+}$} \\
\hline 829.5 & TAG $(50: 4)$ \\
\hline 836.6 & {$[\mathrm{PC}(40: 5)+\mathrm{H}]^{+}$} \\
\hline 855.7 & TAG $(50: 1)$ \\
\hline 857.6 & TAG $(50: 0)$ \\
\hline 881.7 & TAG $(52: 2)$ \\
\hline 883.7 & TAG $(52: 1)$ \\
\hline 903.7 & TAG (54:5) \\
\hline
\end{tabular}

Identification based on LIFT data, literature [21,22,37,38], and two lipid databases (http://lipidsearch.jp or www.lipidmaps.org/).

Abbreviations: PC, phosphatidylcholines; PC with a lower case $e$ and/or $p$ refer to plasmanyl and plasmenyl subspecies, respectively; PE, phosphatidylethanolamine; SM, sphingomyelins; TAG, triacylglycerol. 